\title{
Structural Characterisation of the $E$. coli Heat Stable Enterotoxin STh
}

\author{
Irena Matecko ${ }^{1}$, Bjoern M. Burmann ${ }^{1}$, Kristian Schweimer $^{1}$, Hubert Kalbacher ${ }^{2}$, Jürgen Einsiedel ${ }^{3}$, \\ Peter Gmeiner ${ }^{3}$ and Paul Rösch ${ }^{*}, 1$
}

\author{
${ }^{I}$ University of Bayreuth, Department of Biopolymers \& Research Center for Bio-Macromolecules, D-95440 Bayreuth, \\ Germany \\ ${ }^{2}$ PANATecs GmbH, Vor dem Kreuzberg 17, D-72070 Tübingen, Germany \\ ${ }^{3}$ Department of Medicinal Chemistry, Friedrich-Alexander-University Erlangen - Nürnberg, Schuhstrasse 19, D-91052 \\ Erlangen, Germany
}

\begin{abstract}
E$. coli heat stable enterotoxin STa is an agonist of the membrane guanylate cyclase C whose endogenous ligands are the peptide hormones guanylin and uroguanylin. Whereas these peptides contain only two disulfide bonds, STa is stabilized by one additional disulfide bridge. We chemically synthesized the enterotoxin STh that originates from the $E$. coli strain found in humans, and we determined its structure and its dynamics by nuclear magnetic resonance spectroscopy and molecular dynamics calculations. Chemical synthesis clearly proved successful and resulted in the formation of the native disulfide bonds. The endogenous ligands guanylin and uroguanylin show the same general structural features and dynamics properties as the enterotoxin.
\end{abstract}

Keywords: Enterotoxin, guanylyl cyclase, STh, STa, guanylin, uroguanylin.

\section{INTRODUCTION}

Many bacterial pathogens synthesize toxins that serve as virulence factors. Recently, these toxins became a topic of interest as a medication [1-3], inactive toxin components (toxoids) were suggested to be used as as a vaccine [4], toxins were used as tools to elucidate the complex events during signal transduction [5], even as tumor markers and potential therapeutics in the treatment of colorectal and breast cancer [6-8].

Enterotoxigenic E. coli bacteria (ETEC) produce two forms of heat-stable enterotoxins: STa (or STI) and STb (or STII) $[9,10]$. These toxins cause acute and secretory diarrhea in humans, known as traveler's disease. In developing countries, this type of diarrhea is a major cause of death of infants [11]. STa consists of two subtypes that differ slightly in amino acid sequence and that are, for historic reasons, called STh (originally thought to occur in human E. coli strains only) and STp (originally thought to occur in porcine E. coli strains only).

STh is expressed as a precursor protein of 72 amino acids and it is cleaved twice before it is secreted as the mature 19 amino acid toxin [12-15]. The toxic domain of STh is located in its carboxy-terminal region, between C6-C18, and it is highly conserved within the whole toxin family [5]. The 6 cysteins in this domain are arranged in three disulfide bridges, C6-C10, C7-C15 and C11-C18 [10] (Fig. 1) that are crucial for the peptide's toxicity $[16,17]$. The same disulfide pattern and, generally, high sequence similarity is observed

*Address correspondence to this author at the University of Bayreuth, Department of Biopolymers \& Research Center for Bio-Macromolecules, D95440 Bayreuth, Germany; E-mail: roesch@unibt.de in guanylin and uroguanylin (Fig. 1), the endogenous peptide hormones that physiologically target the same receptor, membrane guanylate cyclase $\mathrm{C}$, which is located at the brush border of the surface of cells of the intestine, and STh is able to displace both of these hormones from their receptor binding site [5,18-22].

$$
\operatorname{STh}(6-19) \text { (E.coli) }
$$

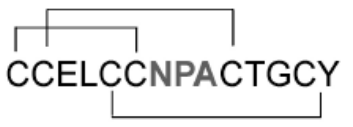

Guanylin (human)

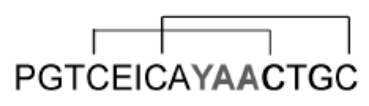

Uroguanylin (human)

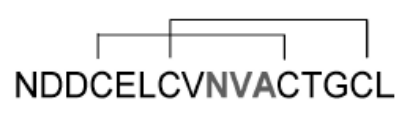

Fig. (1). Comparison of the amino acid sequences and disulfide bridge patterns of the heat stable enterotoxin from the human strain of enterotoxigenic E. coli and human hormones guanylin and uroguanylin. Possible binding region of the peptides are marked gray.

The initial step for the biological effect of STa is its binding to the extracellular domain of GC-C. This interaction leads to over activation of the intracellular GC-C cGMP kinase, which, in turn, results in an excessive signal to the cystic fibrosis transmembrane conductance regulator on the apical plasma membrane of small intestinal enterocytes that, in turn, elicits extreme chloride and fluid secretion $[5,20,23,24]$.

Although the interaction of STa with GC-C is of crucial importance to this process, little is known about its molecu- 
lar basis, and only a crystal structure (PDB: 1ETN, [25]) and an NMR solution structure of STI are known [26]. We are currently examining the structural basis of STh recognition by GC-C, and, as an initial step, we determined the solution structure of the chemically synthesized STh(6-19).

\section{ENTEROTOXIN SYNTHESIS AND REFOLDING}

The synthesis of STh(6-19) was performed using the Fmoc/But and maximal temporary protection strategy on a Syro II peptide synthesizer (MultiSynTech, Witten, Germany). The chemical procedure used $0.05 \mathrm{mmol}$ of Fmoc$\operatorname{Tyr}(\mathrm{tBu})$-2-chlorotrityl resin, an eightfold excess of each amino acid (Fmoc Cys(Trt)-OH, Fmoc-Gly-OH, Fmoc$\mathrm{Thr}(\mathrm{tBu})-\mathrm{OH}$, Fmoc-Ala-OH), Fmoc-Pro-OH, FmocAsn(Trt)-OH, Fmoc-Leu-OH and Fmoc-Glu(OtBu)-OH and 2-(1H-benzotriazole-1-yl)1,1,3,3-tetramethyluronium tetrafluoroborat/1-hydroxybenzotriazole (TBTU/HOBt) activation. Deprotection $(2 \mathrm{~h})$ and cleavage $(100 \mathrm{mg}$ peptide of resin) were achieved using $5 \mathrm{ml}$ of a mixture of trifluoroacetic acid/thioanisole/ethandithiole $(90 / 8 / 2, \mathrm{vol} / \mathrm{vol} / \mathrm{vol})$. The acidic mixture was then precipitated three times with diethylether, dissolved in $10 \%$ aqueous acetic acid and freeze dried. The crude toxin was purified by RP-HPLC on a C18 semi-preparative column (10 x $150 \mathrm{~mm}$; Nucleosil) using a 40 -min gradient of acetonitrile in $0.055 \%$ trifluoroacetic acid $(10-80 \% \mathrm{~B}$ in $40 \mathrm{~min}$, where $\mathrm{B}$ is $80 \%$ acetonitrile $/ \mathrm{H}_{2} \mathrm{O} / 0.05 \%$ trifluoroacetic acid).

Oxidation of the reduced toxin was achieved by dissolving the purified peptide into $2 \mathrm{M}$ acetic acid, and diluted to a peptide concentration of $0.015 \mathrm{mM}$ in the presence of reduced/oxidized glutathione (molar ratio of peptide/GSH/GSSG was 1: 100: 10) and 2 M guanidine hydrochloride. The solution was adjusted to $\mathrm{pH} 8.0$ with aqueous $\mathrm{NH}_{4} \mathrm{OH}$ and stirred slowly at $4{ }^{\circ} \mathrm{C}$ for $7 \mathrm{~d}$. The folding reaction was monitored by analytical HPLC. The solution was concentrated using a C18 SepPak (Waters) cartridge and finally lyophilized. Initial purification of the oxidized product was achieved by chromatography on a C8 column using the system above and yielding a purity of $\sim 90 \%$. Finally, the product was highly purified on a $\mathrm{C} 18$ column using a 60 min gradient, resulting in a purity of $95 \%$. The quality of the product was confirmed by analytical HPLC, matrix-assisted laser desorption/ionization time of flight mass spectrometry (MALDI-MS) giving the correct mass in excellent agreement of the oxidized product. $(\mathrm{M}+\mathrm{H}+)_{\text {calc }}$ reduced: 1482.45 ; found: 1482.42; $(\mathrm{M}+\mathrm{H}+)_{\text {calc }}$ oxidized: 1476.41; found 1476.43 .

\section{NMR SPECTROSCOPY}

Two-dimensional NMR spectra were recorded on Bruker DRX600 and AV800 spectrometers at $283 \mathrm{~K}$ with standard methods [27]. Standard ${ }^{1} \mathrm{H}-{ }^{1} \mathrm{H}$ correlated spectroscopy (COSY), ${ }^{1} \mathrm{H}^{-}{ }^{1} \mathrm{H}$ total correlated spectroscopy (TOCSY) and ${ }^{1} \mathrm{H}-{ }^{1} \mathrm{H}$ homonuclear Overhauser enhancement spectroscopy (NOESY) were carried out with 4096x512 complex data points with excitation sculpting for water suppression [28] or coherence selection by pulsed field gradients [29]. Presaturation was applied for residual water suppression in experiments with the $\mathrm{D}_{2} \mathrm{O}$ sample. ${ }^{1} \mathrm{H}^{13} \mathrm{C}$ heteronuclear single quantum correlation $\left({ }^{1} \mathrm{H}-{ }^{13} \mathrm{C}\right.$ HSQC) and ${ }^{1} \mathrm{H}-{ }^{13} \mathrm{C}-\mathrm{HMQC}$ TOCSY were used for ${ }^{13} \mathrm{C}$ assignment and validation of the
${ }^{1} \mathrm{H}$ assignments. Peptide concentration was $3 \mathrm{mM}$, pH 3.0 in $\mathrm{H}_{2} \mathrm{O} / \mathrm{D}_{2} \mathrm{O}(9$ : $1, \mathrm{v} / \mathrm{v}, 600 \mu \mathrm{L})$ and in $\mathrm{D}_{2} \mathrm{O}(99.98 \%)$. For measurement in $\mathrm{D}_{2} \mathrm{O}$, STh was lyophilized repetitively from $\mathrm{D}_{2} \mathrm{O}$ to exchange the amide protons and finally dissolved in $\mathrm{D}_{2} \mathrm{O}, \mathrm{pH} 3$. Spectra were processed and analyzed with inhouse software and NMRView 5.2.2 [30].

\section{STRUCTURE CALCULATIONS AND ANALYSIS}

The total number of nontrivial unambiguous cross peaks in NOESY spectra was 190 . The cross peaks were divided into three groups according to their relative intensities: strong with upper distance limit $<0.3 \mathrm{~nm}$; medium, $<0.4$ $\mathrm{nm}$; and weak $<0.5 \mathrm{~nm}$. Structure calculations were performed by using a modified $a b$ initio SA protocol with the X-PLOR-NIH package [31]. The disulfide bonds were included explicitly. For each calculation 30 structures were calculated and 7 structures for each state were selected with the criteria for the lowest overall energy. Rasmol 2.7.3 [32,33] and PyMol [34] were used for molecular presentation. The geometry of the structures was analyzed using PROCHECK-NMR [35-37].

\section{MD-SIMULATIONS}

For further analysis and verification of our structural results we did an $a b$ initio molecular dynamics simulation for STH and the hormones uroguanylin and guanylin [38]. The Amber 9 program package [39] and the $f f 03$ force-field $[40,41]$ were used for the simulations of the three peptides. Each of them was constructed as an elongated peptide chain within the LEaP module of AMBER with the disulfide bonding as the only restraints.

The peptides were solvated in a TIP3P waterbox [42] with the dimensions of $80 \times 60 \times 40 \AA$, and for neutralization of the system sodium counterions were added. Calculations were performed at $286 \mathrm{~K}$ and an external pressure of $1 \mathrm{~atm}$. At this conditions the systems were minimized and equilibrated using the program SANDER. Initially, the whole system was minimized for 1000 steps and the water molecules and the counterions were relaxed around the fixed solute with a 100-ps MD run. The systems were slowly heated stepwise to $286 \mathrm{~K}$ for equilibrating at each temperature. MD production runs of 2-ns duration were then performed for the systems. The MD data was analyzed by using the PTRAJ program. Root mean square deviation (r.m.s.d.) calculations of the heavy atoms were referenced to the NMR-structure of STH and the structures of the hormones deposited in the PDB (Guanylin: 1GUA, Uroguanylin; 1UYA), respectively.

\section{RESULTS AND DISCUSSION}

A detailed and well resolved solution structure of STh is needed for better understanding of processes that are involved into peptide recognition by its receptor. We thus chemically synthesized STh(6-19) and analyzed its NMR spectra. The chemical synthesis resulted in a peptide that was active in binding to the membrane proximal extracellular subdomain of human GCC with a nanomolar dissociation constant (Matecko et al., unpublished).

The amide region of the proton NMR spectrum of STh showed the large dispersion of $2.5 \mathrm{ppm}$ characteristic for a peptide with defined structure (Fig. 2). Using standard through- 


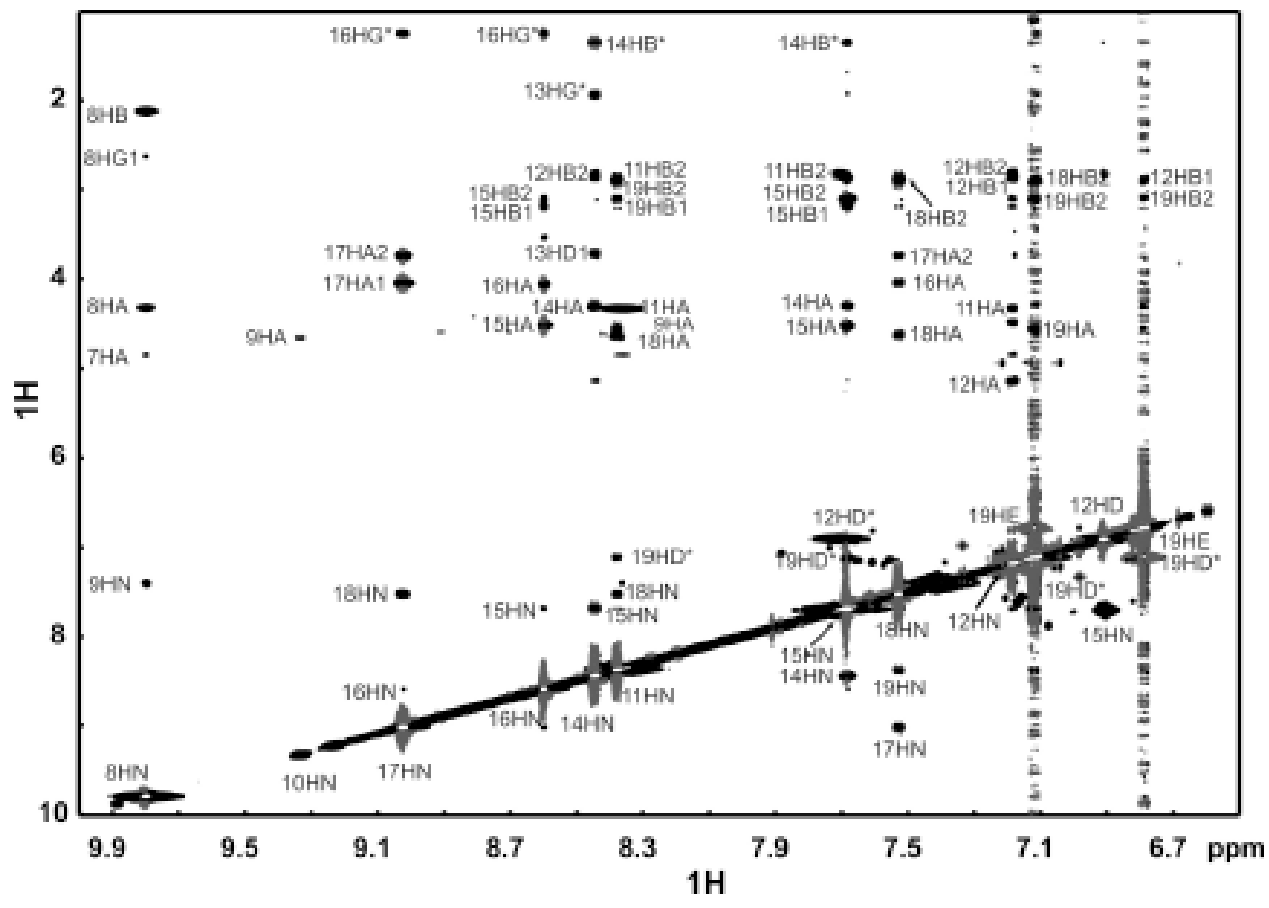

Fig. (2). NOESY spectra of STh(6-19) in $\mathrm{H}_{2} \mathrm{O}, \mathrm{pH} 3.0$ and $288 \mathrm{~K}$.

Table 1. ${ }^{1} \mathrm{H}$ and ${ }^{13} \mathrm{C}$ Chemical Shifts and the Assignment of $\mathrm{STh}(6-19)$ in $\mathrm{H}_{2} \mathrm{O}$ at pH 3.0.

\begin{tabular}{|c|c|c|c|c|c|c|c|c|c|c|c|c|c|}
\hline & HN & HA1 & HA2 & CA & HB1 & HB2 & CB & HG1 & HG2 & CG1 & HD1 & HD2 & CD \\
\hline Glu8 & 9.84 & 4.33 & & 59.30 & 2.15 & 2.15 & 26.70 & 2.64 & 2.43 & & & & \\
\hline Leu9 & 7.41 & 4.66 & & 53.73 & 1.84 & 1.58 & 41.88 & 1.49 & & & 0.94 & 0.87 & 22.79 \\
\hline Cys10 & 9.33 & & & 58.11 & 3.31 & 3.46 & 39.80 & & & & & & \\
\hline Cys11 & 8.38 & 4.33 & & 58.11 & 3.21 & 2.88 & 36.87 & & & & & & \\
\hline Asn 12 & 7.19 & 5.16 & & 51.42 & 2.89 & 2.82 & 41.80 & & & & & & \\
\hline Pro13 & & 4.31 & & 64.55 & 2.28 & 2.28 & 32.10 & 1.97 & & & 3.72 & 3.76 & 51.75 \\
\hline Ala14 & 8.45 & 4.31 & & 52.62 & 1.37 & 1.37 & 18.49 & & & & & & \\
\hline Cys 15 & 7.69 & 4.53 & & 55.53 & 3.18 & 3.11 & 37.91 & & & & & & \\
\hline Thr16 & 8.60 & 4.07 & & 63.92 & 4.08 & & 69.33 & 1.29 & & 21.92 & & & \\
\hline Gly17 & 9.02 & 4.05 & 3.75 & 45.86 & & & & & & & & & \\
\hline Cys 18 & 7.58 & 4.63 & & 56.68 & 2.92 & 2.92 & 39.26 & & & & & & \\
\hline Tyr19 & 8.38 & 4.57 & & 57.95 & 3.11 & 2.91 & & & & & & HE2 & 6.79 \\
\hline
\end{tabular}

Chemical shifts for Cys6, Sys7 could not be determined due to flexibility of amino terminus.

bond and through-space 2D homonuclear and heteronuclear correlation experiments at natural abundance most of the resonances could be assigned (Table $\mathbf{1}$ ), and only the amide proton of $\mathrm{C} 7$ and the resonances of C6 were not identified in the spectra. The severely increased linewidth of amide protons as well as the beta protons of residues $\mathrm{C} 10, \mathrm{C} 11$, L9 likely reflects conformational dynamics on the intermediate chemical shift time scale ( $\mu \mathrm{s}-\mathrm{ms})$. The ${ }^{13} \mathrm{C}$ chemical shifts of cysteines are very sensitive to the oxidation state of the sulfur atom [43]. The $\mathrm{C} \beta$ resonances of $\mathrm{C} 10, \mathrm{C} 11, \mathrm{C} 15$ and $\mathrm{C} 18$ are in the range between $36.9-39.8 \mathrm{ppm}$. This characteristic down field shift indicates the oxidized state of these cysteines. The chemical shift of C7 (33.9 ppm) is in the intermediate region between upfield shifted resonances of re- duced cysteines and downfield shifted resonances of oxided cysteines, the NOE cross peaks between C7-HA and C15HB1,2 protons, however, clearly demonstrate the presence of the disulfide bond between these two residues. From this data it can be deduced that C6 must also be oxidized. Direct observation of the other two disulfide bonds by means of NOE cross peaks was not possible due to overlap with trivial intraresidual signals. The presence of the three disulfide bonds is also consistent with the observed molecular weight by mass spectroscopy (expected mass: 1475.46 Da, measured: $1475.43 \mathrm{Da}$ ). The NOESY cross peaks between P13 $\delta$ protons and the $\alpha$-proton of N12 show the trans conformation of the proline. Slow solvent exchange of amide protons of $\mathrm{C} 11, \mathrm{~N} 12$, and $\mathrm{C} 15$ (Fig. 2) suggests these residues to be 
involved in hydrogen bonds. During the iterative structure determination hydrogen bonds between $\mathrm{N} 12 \mathrm{CO}$ and $\mathrm{C} 15$ $\mathrm{H}^{\mathrm{N}} ; \mathrm{C} 18 \mathrm{H}^{\mathrm{N}}$ and $\mathrm{C} 15 \mathrm{CO}$ and $\mathrm{C} 10 \mathrm{H}^{\mathrm{N}}$ and $\mathrm{C} 7 \mathrm{CO}$ were deduced.

For the structure calculation 190 experimentally derived distance restrains were obtained. Due to the observed line broadening by conformational exchange NOE peak intensities were classified very conservatively to include effects of dynamical averaging. The ten accepted structures out of ten calculated superimpose with a backbone r.m.s.d. of $0.89 \AA$ and show only low violations of experimental and geometrical restraints (Table 2). A PROCHECK-NMR analysis of STh shows that $51 \%$ of the residues of the accepted structures are found in the most favoured regions and an additional $49 \%$ in the allowed regions of the Ramachandran plot (Table 2).

\section{Table 2. Structural Statistics}

\begin{tabular}{|l|c|}
\hline NOE Statistics & \\
\hline \hline Total NOE number & 190 \\
\hline Short range & 21 \\
\hline Medium range & 16 \\
\hline Long range & 153 \\
\hline $\begin{array}{l}\text { Deviation from Standard Geometry and } \\
\text { Experimental Restrains }\end{array}$ \\
\hline \hline Bonds & $0.00095 \pm 0.0002$ \\
\hline Angles & $0.169 \pm 0.023$ \\
\hline Distance restrains & $0.0036 \pm 0.0011$ \\
\hline Ramachandrans plot statistics ${ }^{\mathrm{a}}$ & $51 \% / 31 \% / 18 \% / 0 \%$ \\
\hline
\end{tabular}

${ }^{a}$ Ramachandran plot statistics are determined by PROCHECK-NMR and are determined as follow: residues in most favored region, in additional region, in generously allowed region, and in disallowed region.
The solution structure of STh(6-19) is composed of an $\alpha$ helical turn at its N-termius region and two $\beta$ - turns, between $\mathrm{C} 11-\mathrm{C} 15, \mathrm{C} 15-\mathrm{C} 18$ stabilised by the three disulfide bridges as mentioned before (Fig. 3).

The unavailability of the coordinates of the solution conformation from Gariepy et al. [26] renders direct comparison of the structures impossible. Superimposing the present STh structure with the crystal structure (pdb code 1ETN [25]), however, resulted in a backbone r.m.s.d. of $1.6 \AA$ for residues $\mathrm{C} 7-\mathrm{C} 18$, mainly due to different orientation of the carboxy terminus. Restricting the fit to residues C7-G16 lowers the rmsd to $0.9 \AA$, demonstrating similar conformations in solution and in the crystal. The receptor binding region of STh and the endogenic GC-C pedptide ligands uroguanylin and guanylin is found to be from N12 - A14 for STh [44] and Y9 - A11 for guanylin [45]. In fact, these regions are highly solvent exposed for guanylin, uroguanylin, STp, and STh (Fig. 4).
A

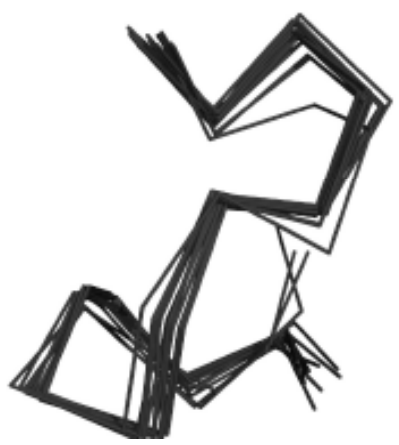

B

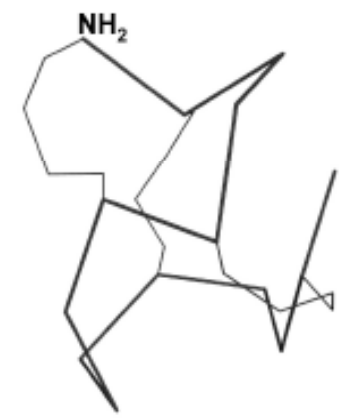

Fig. (3). (A) Overlay of 13 NMR derived structures of STh (6-19). (B) Presentation of disulfide bridges in STh (6-19).

$A b$ initio MD simulations with the NMR structures of guanylin, uroguanylin, and STh as starting structures show high flexibility of all three peptides in the loop regions (Fig.
B

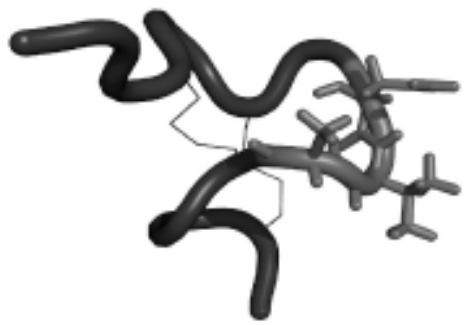

C
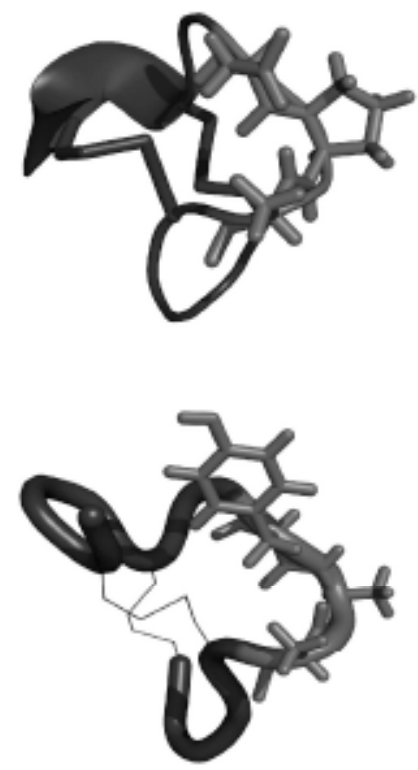

Fig. (4). Comparison of structures of (A) STp (5-17), PDB: 1ETN; (B) Uroguanylin human, PDB: 1UYA; (C) Guanylin human, PDB: 1GNA and (D) our calculated STh (6-19) structure. Possible binding sites are shown as sticks. 
5). The r.m.s.d. values of heavy atoms are in the same range for all three peptides, despite the additional disulfide bridge in STh. To evaluate the importance of the three disulfide bridges for the structure calculation of STh, we performed the identical calculations as we did for the NMR-structure determination, however, without taking into account the disulfide bridges. The energetically most favourable 15 structures were virtually the same as from the calculation containing both, the NOE restraints and the disulfide bridges. The largest difference in the structures was in the N-terminal loop and the carboxy-terminus of the peptide which both were observed to show higher flexibility.

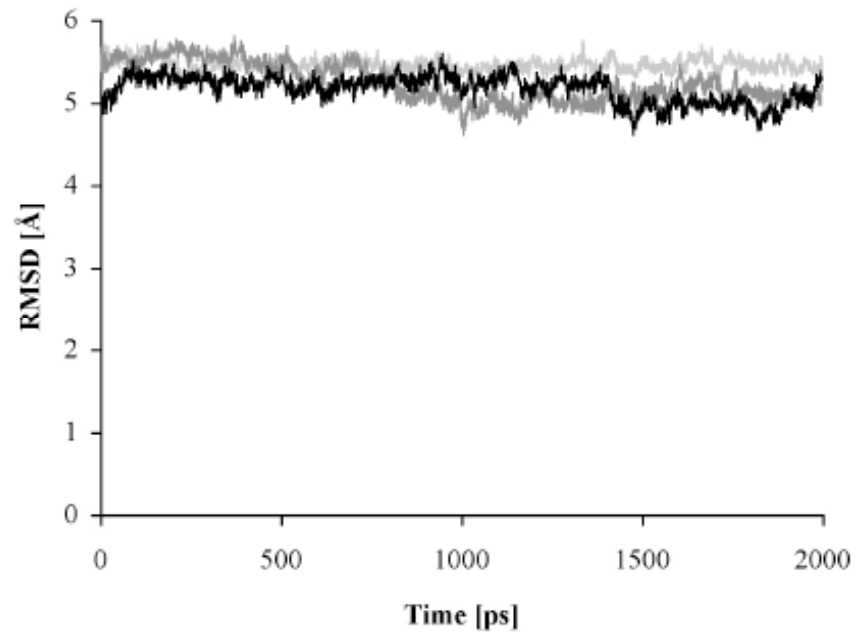

Fig. (5). RMSD of the heavy atoms during the MD. Sth ( 6-19) referenced to the present structure (black); Uroguanylin referenced to PDB: 1UYA (light grey); Guanylin referenced to PDB: 1GNA (dark grey).

In addition to differences in structure and dynamics, STh may act as a toxin because it does not contain the chymotrypsin cleavage site found in guanylin, the endogenous peptide that predominantly acts in the large intestine, as opposed to uroguanylin [45]. Chymotrypsin is an enzyme of the intestinal tract, and it cleaves after aromatic amino acids such as Y9 of guanylin (Fig. 1). In fact, the Y9NA10P double mutant of guanylin causes diarrhoea in suckling mice at much lower concentrations than the native peptide does [45]. Thus, one reason for the only transient action of native guanylin in the large intestine could be its rapid loss of its structure by enzymatic digestion.

\section{ACKNOWLEDGEMENT}

Financial support by the Deutsche Forschungsgemeinschaft to PR (MA2317/5-2) is gratefully acknowledged.

\section{REFERENCES}

[1] Carter SR, Seiff SR. Cosmetic botulinum toxin injections. Int Ophthalmol Clin 1997; 37: 69-79.

[2] Levine SR. Thrombolytic therapy for stroke: the new paradigm. Hosp Pract (Minneap) 1997; 15; 32(11): 57-64, 69-73.

[3] Maseri A, Andreotti F. Targeting new thrombolytic regimens at specific patient groups: implications for research and costcontainment. Eur Heart J 1997; 18(Suppl F): F28-35.

[4] Schmitt CK, Meysick KC, O'Brien AD. Bacterial toxins: friends or foes? Emerg Infect Dis 1999; 5: 224-34.

[5] Hasegawa M, Shimonishi Y. Recognition and signal transduction mechanism of Escherichia coli heat-stable enterotoxin and its receptor, guanylate cyclase C. J Pept Res 2005; 65: 261-71.
[6] Giblin MF, Gali H, Sieckman GL, et al. In vitro and in vivo evaluation of 111In-labeled E. coli heat-stable enterotoxin analogs for specific targeting of human breast cancers. Breast Cancer Res Treat 2006; 98: 7-15.

[7] Giblin MF, Sieckman GL, Shelton TD, Hoffman TJ, Forte LR, Volkert WA. In vitro and in vivo evaluation of $177 \mathrm{Lu}-$ and $90 \mathrm{Y}-$ labeled $E$. coli heat-stable enterotoxin for specific targeting of uroguanylin receptors on human colon cancers. Nucl Med Biol 2006; 33: 481-8.

[8] Giblin MF, Sieckman GL, Watkinson LD, et al. Selective targeting of $E$. coli heat-stable enterotoxin analogs to human colon cancer cells. Anticancer Res 2006; 26: 3243-51.

[9] Shimonishi Y, Hidaka Y, Koizumi M, et al. Mode of disulfide bond formation of a heat-stable enterotoxin (STh) produced by a human strain of enterotoxigenic Escherichia coli. FEBS Lett 1987; 215: 165-70.

[10] Nair GB, Takeda Y. The heat-stable enterotoxins. Microb Pathog 1998; 24: 123-31.

[11] Levine MM, Caplan ES, Waterman D, Cash RA, Hornick RB, Snyder MJ. Diarrhea caused by Escherichia coli that produce only heat-stable enterotoxin. Infect Immun 1977; 17: 78-82.

[12] Moseley SL, Hardy JW, Hug MI, Echeverria P, Falkow S. Isolation and nucleotide sequence determination of a gene encoding a heatstable enterotoxin of Escherichia coli. Infect Immun 1983; 39: 1167-74.

[13] Lee CH, Moseley SL, Moon HW, Whipp SC, Gyles CL, So M. Characterization of the gene encoding heat-stable toxin II and preliminary molecular epidemiological studies of enterotoxigenic Escherichia coli heat-stable toxin II producers. Infect Immun 1983; 42: 264-8.

[14] Rao MC. Toxins which activate guanylate cyclase: heat-stable enterotoxins. Ciba Found Symp 1985; 112: 74-93.

[15] Lathe R, Hirth P, DeWilde M, Harford N, Lecocq JP. Cell-free synthesis of enterotoxin of $E$. coli from a cloned gene. Nature 1980; 284: 473-4.

[16] Gariepy J, Judd AK, Schoolnik GK. Importance of disulfide bridges in the structure and activity of Escherichia coli enterotoxin ST1b. Proc Natl Acad Sci USA 1987; 84: 8907-11.

[17] Yoshimura S, Ikemura H, Watanabe H, et al. Essential structure for full enterotoxigenic activity of heat-stable enterotoxin produced by enterotoxigenic Escherichia coli. FEBS Lett 1985; 181(1): 138-42.

[18] Hirayama T, Wada A, Hidaka Y, Fujisawa J, Takeda Y, Shimonishi Y. Expression of a truncated guanylate cyclase (GC-C), a receptor for heat-stable enterotoxin of enterotoxigenic Escherichia coli, and its dimer formation in COS-7 cells. Microb Pathog 1993; 15: 283-91.

[19] Waldman SA, Kuno T, Kamisaki Y, et al. Intestinal receptor for heat-stable enterotoxin of Escherichia coli is tightly coupled to a novel form of particulate guanylate cyclase. Infect Immun 1986; 51:320-6.

[20] Hasegawa M, Hidaka Y, Matsumoto Y, Sanni T, Shimonishi Y. Determination of the binding site on the extracellular domain of guanylyl cyclase C to heat-stable enterotoxin. J Biol Chem 1999; 274: 31713-8.

[21] Wada A, Hirayama $\mathrm{T}$, Kitaura $\mathrm{H}$, et al. Identification of ligand recognition sites in heat-stable enterotoxin receptor, membraneassociated guanylyl cyclase $\mathrm{C}$ by site-directed mutational analysis. Infect Immun 1996; 64: 5144-50.

[22] Hasegawa M, Matsumoto-Ishikawa Y, Hijikata A, Hidaka Y, Go M, Shimonishi Y. Disulfide linkages and a three-dimensional structure model of the extracellular ligand-binding domain of guanylyl cyclase C. Protein J 2005; 24(5): 315-25.

[23] Gardner P, Chao AC, De Sauvage F. STa receptors: Physiological and pathophysiological regulation of intestinal secretion by 5 'cyclic guanosine monophosphate. Gastroenterology 1995; 109(1): 325-7.

[24] Harteneck C, Koesling D, Soling A, Schultz G, Bohme E. Expression of soluble guanylyl cyclase. Catalytic activity requires two enzyme subunits. FEBS Lett 1990; 272: 221-3.

[25] Ozaki H, Sato T, Kubota H, Hata Y, Katsube Y, Shimonishi Y. Molecular structure of the toxin domain of heat-stable enterotoxin produced by a pathogenic strain of Escherichia coli. A putative binding site for a binding protein on rat intestinal epithelial cell membranes. J Biol Chem 1991; 266: 5934-41. 
[26] Gariepy J, Lane A, Frayman F, et al. Structure of the toxic domain of the Escherichia coli heat-stable enterotoxin ST I. Biochemistry 1986; 25: 7854-66.

[27] Cavanagh J, Fairbrother WJ, Palmer III AG, Skelton NJ. Protein NMR Spectroscopy: Principles and Practice. San Diego, CA: Academic Press; 2006.

[28] Hwang TL, Shaka AJ. Water suppression that works. Excitation sculpting using arbitary wave forms and pulsed gradients. J Magn Res 1995; 112A: 275-9.

[29] Mori S, Abeygunawardana C, Johnson MO, van Zijl PC. Improved sensitivity of HSQC spectra of exchanging protons at short interscan delays using a new fast HSQC (FHSQC) detection scheme that avoids water saturation. J Magn Res B 1995; 108: 94-8.

[30] Johnson BA. Using NMRView to visualize and analyze the NMR spectra of macromolecules. Methods Mol Biol 2004; 278: 313-52.

[31] Schwieters CD, Kuszewski JJ, Tjandra N, Clore GM. The XplorNIH NMR molecular structure determination package. J Magn Res 2003; 160: 66-74.

[32] Bernstein HJ. Recent changes to RasMol, recombining the variants. Trends Biochem Sci 2000; 25: 453-5.

[33] Sayle R, Milner-White EJ. RASMOL: Biomolecular graphics for all. Trends Biochem Sci 1995; 20: 374-6.

[34] DeLano WL. The PyMOL Molecular Graphics System. DeLano Scientific, Palo Alto, CA, USA. 2002.

[35] Morris AL, MacArthur MW, Hutchinson EG, Thornton JM. Stereochemical quality of protein structure coordinates. Proteins 1992; 12: 345-64.

[36] Laskowski RA, MacArthur MW, Moss DS, Thornton JM. PROCHECK: A program to check the stereochemical quality of protein structures. J Appl Cryst 1993; 26: 283-91.
[37] Laskowski RA, Rullmannn JA, MacArthur MW, Kaptein R, Thornton JM. AQUA and PROCHECK-NMR: Programs for checking the quality of protein structures solved by NMR. J Biomol NMR 1996; 8: 477-86.

[38] Simmerling C, Strockbine B, Roitberg AE. All-Atom Structure Prediction and Folding Simulations of a Stable Protein. J Am Chem Soc 2002; 38: 11258-9.

[39] Case DA, Darden TA, Cheatham TE, et al. AMBER 9, University of California, San Francisco, 2006.

[40] Duan Y, Wu C, Chowdhury S, et al. A point-charge force field for molecular mechanics simulations of proteins based on condensedphase quantum mechanical calculations. J Comput Chem 2003; 24 : 1999-2012.

[41] Lee MC, Duan Y. Distinguish protein decoys by using a scoring function based on a new AMBER force field, short molecular dynamics simulations, and the generalized born solvent model. Proteins: Struct Funct Bioinf 2004; 55: 620-34.

[42] Price DJ, Brooks III CL. A modified TIP3P water potential for simulation with Ewald summation. J Chem Phys 2004; 121: 10096103.

[43] Sharma D, Rajarathnam K. ${ }^{13} \mathrm{C}$ NMR chemical shifts can predict disulfide bond formation. J Biomol NMR 2000; 18: 165-7.

[44] Carpick BW, Gariepy J. Structural characterization of functionally important regions of the Escherichia coli heat-stable enterotoxin STIb. Biochemistry 1991; 30: 4803-9.

[45] Carpick BW, Gariepy J. The Escherichia coli heat-stable enterotoxin is a long-lived superagonist of guanylin. Infect Immun 1993; 61: 4710-5.

This is an open access article licensed under the terms of the Creative Commons Attribution Non-Commercial License (http://creativecommons.org/licenses/by$\mathrm{nc} / 3.0 /$ ) which permits unrestricted, non-commercial use, distribution and reproduction in any medium, provided the work is properly cited. 